\title{
On the Ethnic Factors in the Piano Works of Jiang Wenye
}

\author{
Qi Ling ${ }^{1}$ \\ ${ }^{1}$ School of Music, Hubei Engineering University
}

Key words: Jiang Wenye, Piano works, Ethnic factors

\begin{abstract}
As a remarkable composer in Chinese modern music creation history, Jiang Wenye had many works involved in many sectors, among which the most extraordinary is that his piano works is well-accepted and highly praised by people for its large number and excellent quality. Therefore, Jiang Wenye had been a representative person in the creation of piano music in 1930s and 1940s. This paper makes profound analysis on the evolution of the music styles of Jiang Wenye's piano works in different stages and the presentation of ethnic factors in them by combining with his personal life experience; and then makes comments for the combination of Chinese and western styles in Jiang Wenye's piano works to emphasize his major contributions and the important status of its works.
\end{abstract}

\section{Introduction}

The development of global culture is based on the development of national culture all over the world for what ethnic is what worldwide. Global culture is closely relevant to ethnic culture and reflects the politics, economy, science and arts of different nations in cultural arts, thus leaving precious treasure in the civilization history of human beings. Under most conditions, ethnic culture with rapid development will have more important influence of world culture. Therefore, in 18th century, China and other Asian countries tied by feudal system presents the feature of combination of China and foreign countries. Chinese music and Japanese music belong to the same musical system. The integration of Chinese and western culture exists in the ethnic music with the same musical system and different musical systems. And Chinese traditional musicians fully play their talents under such situation and make their contributions to the development of ethnic culture.

\section{The life experience and musical achievements of Jiang Wenye}

Born in Taiwan, Jiang Wenye finished his earlier education in Xiamen, Fujian and then furthered his study when he was 13 years old and obtained western music education in Japan, which led to his career as professional musician. Therefore, Japan was an important turning point in his growth and had significant influence on his life, which could be proved by the profound Japanese musical elements in his early music works. In 1910 when Jiang was born, Taiwan was under the control of Japan, so he stood in the music field as a Japanese musician at the early stage. Until later, the Chinese residents who lived in Taiwan were so badly depressed that he saw through the truth of history. And motivated by various social conflicts, he took the teacher post of Beiping Normal University and then lived in mainland China as a genuine Chinese musician. Then in 1945, China succeeds in the anti-Japanese war and Taiwan returned back to China. Jiangwenye was little affected for he only lived in Taiwan for a short time in his childhood. From the music works created by Jiang Wenye, most his cognition for Taiwan comes from subjective imagination instead of real 
observation, which is quite different from other overseas students who learned in Japan, such as $\mathrm{Li}$ Shutong and Shen Xingong. As early as 1936, Jiang Wenye came to mainland China following Tcherepnin and contacted with the folk culture and customs in China, which is reflected in his works. However, it can be seen that his understanding for Chinese culture at that stage is superficial. Until he settled down in Beiping in 1938, Jiang Wenye was really a part of his motherland and finally became a Chinese Taiwanese musician.

The music creation of Jiang Wenye has wide topics and he also wrote many musical theory masterpieces. It can be said that he is a music master with both music composition and theory and his musical achievements consist of the following three aspects. 1. Invention of vocal musical works. Jiang has been a famous vocal musical performer before being a famous composer. And the most famous works in his early stage is Song for Compatriots in mountain Taiwan finished in 1936. And it based on the reference to western musical performance method, it concisely expressed to rough life and heroic feelings of the people in mountainous district. After he settled down in Beiping in 1938, his works incline to be ballad and wrote the famous Chinese Ballad Collection, which has profound influence for the descendents. 2. Invention of musical instruments. The instrumental music is an important part of his achievements, which represents the highest part of art achievements. His early instrumental works consists of orchestral music Fantasy of Bailu and Formosan Dance created in 1934. On August, 1938, Jiang returned back to mainland China and created a series of piano composition such as The Peking Myrioram to express his true feelings. After emancipation, Jiang is active in music and strive to conform to the features of new times in expression, and created pianolude Happy Childhood and Ode to Spring to express the longingness for new life and enthusiasm. 3. Theory study and music teaching. Jiang Wenye interpreted the real meaning of unity of heaven and man by his own real musical practice on the basis of Chinese traditional Confucius music and combining with the learned western music skills to form his deep understanding for traditional music culture. During his music teaching, he stood in the front line and edited many useful piano lessons and cultivated many excellent students.

\section{Ethnic factors in the Piano music creation of Jiang Wenye}

During the development process of the development for Chinese contemporary piano music, many young composers make countless contributions to it. In that period, the piano music works of Jiang Wenye comes to its peak. However, the difficulty in economy during the growing process, Jiang could not integrate with other composers for a long time and maintained his uniqueness, which plays significant importance for study the ethnic factors in his piano creation.

The piano creation in early stage of Jiang Wenye. In the early stage of his piano creation, Jiang wrote about 10 influential works, among which 5 were timely published. At this stage, Jiang Wenye was the most confident for his talents and future and he stepped into various musical works which won prizes in Europe and Japan. As a beginner in composition, his works were full of the romantic and ethnic style. And the genre in his piano works often stimulated impressionism masters and mainly emphasized the customs in Japan. For example, all the five sketches and the Sixteen Bagatelles. The first chapter The One Legged Scarecrow in the Mount Field, the second In the field behind the house, the third Round the Camp Fire We Dance, the forth In the Sidestreets, and the 
fifth Full Sail among the Five Sketches of Piano Music; another example is the first chapter Green Leaves, the forth Reed of Hawkers sell sugar, and the seventh Tombstone Inscription of the Sixteen Bagatelles.

His creation enthusiasm aroused the attention of Tcherepnin who lived in Shanghai and Japan and finally they set up teacher-student relationships. And Tcherepnin was fascinated with Chinese culture. In 1936, Jiang lived in mainland China for half a year and devoted all his creation enthusiasm after contacting widely with Chinese folk music and customs. This awakening of ethnic consciousness is reflected in Sixteen Bagatelles. And the 11th Afternoon Chinese Violin, 15th Moonlight Pipa and 16th Beijing Zhengyang Gate are named with titles of Chinese impression.His music had obvious Chinese taste and became the beginning from Japanese style to the combination of China and western countries.

Then in 1938, Jiang taught in Beiping Normal University and finished 10 bagatelles of his violin divertimento among The Peking Myrioram, which expressed the folk and customs of old Beijing. Such as Sound of a Little Drum, In Front of the Forbidden City, Tian'an Men(the Gate of Heavenly Peace), Willows and $<$ Midnight,in Sajik altar $>$, etc. In this music works, ethical elements of music language and the Sixteen Bagatelles created before were of more sinification, especially works like Tian'an Men(the Gate of Heavenly Peace), In Front of the Forbidden City and The Dragon Stele. For example, in dramatic rhythms of catkin, it was full of Beijing Opera under the comparison of bass, which is full of typical Chinese factors. And other work, the creators involve the rhythms of Jiangsu folk song in to and achieved excellent artistic effect.

The piano creation in later stage of Jiang Wenye. After settled down in Beiping in 1938, Jiang studied the Chinese culture apart from daily teaching and transferred the emphasis to the study on Chinese folk song and ancient poets and finally created many solo and accompanies. This stage lasts for over 20 years and at this stage, Jiang's works are not abundant. Works at these stages have more ethnic factors compared with the creation when he lived in Japan, which is mainly reflected in the following aspects.

Firstly, he takes Chinese ethnic music as the basis for the music language of piano works. Therefore, his works are full of ethnic features. For example the two, Third Sonata "South of the Yangtze river” and Ballade - Deyang Moonlight, both adopt China ancient pipa-Deyang Moonlight as basic melodies, Fourth Sonata - Carnival Day adopts northern shaanxi folk song -Blue Orchid and Hebei yangko dance, Piano Sonata —-Dianyue adopts Guzheng music of Beiwei 《Dianyue》, and Piano Fantasy Song - Fisherman Song adopts the acientFisherman's Song at Dusk and so on. Sonata No. 3--views of southeast China and Piano narration--moon-night in Deyang, all adopts the basic tone of ancient Pipa composition moon-night in Deyang; while the Sonata No. 4 adopts the folk song in North Shaanxi as basic tone. Secondly, the harmonic language conforms to the traditional tones in China, which is expressed more plain and traditional and does not adopts the features of western romanticism. The design purpose of harmonic language is to advocate the ethnic factors of traditional Chinese music instead of exploring the design of western music, which is simple and kind. Thirdly, the topic selection of the works have wider perspectives, which is not limited to the music presentation methods of modern western Neo-Nationalism and then he expanded the tones of traditional Chinese instruments and combines skillfully so as to make ethnic factors lying in it. Fourthly, it makes breakthrough changes in the composition structure. In the previous, Jiang inclines to apply the creation methods of comedy collections. With the development of times, it urges that the musical creation of Jiang Wenye changes towards large composition structure from Chinese ethnic-based tones. In his later sonata, he abandoned the traditional structure 
of European sonata and adopts the perspective of overall structure to conceive under the basis of same tone. For example, Jiang Wenye revised his Sonata No. 3--views of southeast Chin and gave up the structure of its original three movements. Then he changed to sonata into piano narration and gave up the title of views of southeast China into moon-night in Dejiang so as to confer the profound Chinese factors to the traditional Pipa music. The various changes indicate that Jiang Wenye intended to realize true combination of Chinese features and western features to promote the traditional ethnic factors in China. As the various barriers during creation process, he even chose to temporarily give up the mature skills in western music creation so as to realize the significance of expanding Chinese traditional styles, therefore, his love for Chinese traditional culture can be seen.

\section{Significance of combination of Chinese and Western elements in Jiang Wenye's piano music}

During the early stage of Jiang Wenye's creation, he firstly learned mature composition theory and skills in western which laid profound foundation for his later creation. It is undoubtedly that he was deeply affected by western culture. When he finally came back to his motherland-China and facing the thousand years splendid and rich civilization in China, Jiang Wenye made up his mind to give up the shackles of western traditional music creation and presented the original Chinese features during the creation of music works. He saved himself from the crisis and realized high-level innovation spirit in different music culture, which is, undoubtedly, worthwhile of learning for the later generations. Therefore, study on the ethnic factors in his piano creation is of particularly significance.

During the previous stage of his creation, he was mostly affected by the folk customs in Japanese culture and the music culture presented in their works is low and full of vitality. However, in the later creation stage, he turned his attention to the music and culture of ancient China, which decides the high standards of his later creation. And correspondingly, the flavor of life is narrowed down and the vitality becomes weak correspondingly, which determines that the reflected artistic ideas in his later works concentrates too much on ancient and less on the life in reality, which is a pity.

\section{Conclusion:}

With the increasing study on the integration of western and eastern culture in recent years, the repeated communication of Chinese and western culture in 20th century is the main reason for promoting the constant development of world music. In contemporary stage, Chinese composers should absorb the advantageous experience of western music and finally create modern music works with eastern features and ethnic styles. The life of Jiang Wenye strived for the achievement of this goal by his real action. As for this efforts and contributions, success or failure, are full of value as the wealth for further process of descendants.

\section{Acknowledgement}

This paper is Hubei province education department humanistic and social science research achievement. Project title: Research of Chinese Piano Music National Character in the First Half of the 20th Century. Project number:14Q098.

\section{References:}


[1]Lei Meiqin. Exploration and development of Chinese style and extension of creation styles of Jiang Wenye ---Comparison study on Jiang Wenye's piano works Beijing Wanhua Collection [D]. Capital Normal University in Beijing, 2002 (In Chinese)

[2]Hu Ximin. Excellent Chinese musician--Jiang Wenye [M]. Hongkong: Hongkong Shanghai Publishing House, 1985 (In Chinese)

[3] Liang Maochun. Chinese contemporary music1949-1989 [M]. Beijing: Beijing Broadcast Institute Publishing House, 1993 (In Chinese)

[4] Liang Maochun \& Jiang Xiaoyun. Discussion on Jiang Wenye [J]. Central Conservatory of Music in Beijing Publishing House,2000 (In Chinese)

[5] Wan Yaohua. Brief Introduction to Chinese traditional music [M]. Taipei: Taipei hitom enterprise culture co., LTD ,1990 (In Chinese)

[6] Xiang Yansheng. Biography for Chinese contemporary musician [M]. Shenyang: Chunfeng Literature and Art Publishing House, 1994 (In Chinese)

[7] Wang Yuhe. Brief introduction to mainland music creators in 20th century [J]. Explorations in Music,1995 (1) (In Chinese)

[8] Editorial Board for Chinese encyclopedia. Music \& Dance Editorial Board for Chinese encyclopedia [M]. Encyclopedia of China Publishing House, 2004

[9]Wang Niyi. Century Documents for Music Aesthetics in China for Yang Heping [M]. Beijing Modern Publishing House, 2000 (In Chinese) 